\title{
Prevalence of Obesity and its Relation with Eating Habits and Lifestyle among Male Primary Schoolchildren in Al-Madinah City, Saudi Arabia
}

\author{
AWAD MOHAMMED AL-QAHTANI, M.D., S.B.F.M., A.B.F.M. \\ The Department of Family \& Community Medicine, College of Medicine, Najran University, Saudi Arabia
}

\begin{abstract}
Objective: To investigate lifestyle and dietary habits associated with development of obesity among male primary school children in Al-Madinah City, Saudi Arabia.

Methods: A cross sectional study was conducted in AlMadinah City that included 201 male primary school students aged above 8 years. The researcher used a study questionnaire that comprised socio-demographic variables and the HABITS questionnaire. Anthropometric measurements were also recorded to calculate the Body Mass Index (BMI).
\end{abstract}

Results: The mean age of participants (SD) was 11.22 $( \pm 1.1)$ years. Prevalence of obesity among participants was $19.4 \%, 59.7 \%$ of male primary schoolchildren ate three meals daily. Only $16.9 \%$ ate fruits daily, $17.9 \%$ ate vegetables daily, while $88.1 \%$ ate snacks between meals and $20.4 \%$ consumed soft and energy drinks once daily, while $10.4 \%$ consumed soft and energy drinks twice or several times daily. One third of male primary schoolchildren watched TV for 3 hours or more, while during weekends, $66.2 \%$ watched TV for 3 hours or more. Regarding outdoor activity, $29.9 \%$ practiced it once a day, while $18.9 \%$ practiced it more than once a day.

Consumption of soft and energy drinks was significantly higher among obese participants than non-obese ones ( $p=$ 0.035 ), and outdoor activity was significantly higher among non-obese participants than obese ones $(p=0.027)$.

Conclusions: Bad nutritional habits are common among male primary schoolchildren. Prevalence of obesity among male primary school children is high and increases with their age. Consumption of soft and energy drinks and lack of physical activity are associated with obesity among children. Therefore, there is a pressing need for the development of effective obesity prevention programs for schoolchildren.

Key Words: Obesity - Schoolchildren - Food habits - Body mass index-Physical activity.

Correspondence to: Dr. Awad Mohammed Al-Qahtani, The Department of Family \& Community Medicine, College of Medicine, Najran University, Saudi Arabia

\section{Introduction}

THE Centers for Disease Control and Prevention (CDC) defined overweight as at or above the 95 th percentile of Body Mass Index (BMI) for age and "at risk for overweight" as between 85 th to $95^{\text {th }}$ percentile of BMI for age [1]

The World Health Organization (WHO) estimated that by the year 2020, non-communicable diseases will become the principal global cause for morbidity and mortality, and considered obesity as a global epidemic for both adults and children [2] . Obesity is a major risk factor for illness and death. It is associated with diabetes, hypertension, hyperlipidemia, obstructive sleep apnea, and osteoarthritis [3]. With the increase in life expectancy, obesity is causing more years of disability [4].

Childhood obesity has become a new challenge for healthcare providers. Its prevalence is increasing worldwide. The causes of obesity are poorly understood and continue to be debated and studied. The increased consumption of more energy-dense, nutrient-poor foods with high levels of sugar and saturated fats, combined with reduced physical activity, have led to high obesity rates among children [5].

Prevalence of child obesity is increasing at an alarming rate. In 2007, an estimated 22 million children under the age of 5 years were overweight throughout the world [2].

There are multiple etiologies for childhood obesity. Genetic factors influence the susceptibility of a given child to an obesity-conducive environment. However, environmental factors, lifestyle preferences, and cultural environment seem to play major roles in the rising prevalence of obesity 
worldwide [6]. In a small number of cases, childhood obesity is due to genes such as leptin deficiency or medical causes such as hypothyroidism and growth hormone deficiency or side effects due to drugs like steroids. Most of the time, however, personal lifestyle choices and cultural environment significantly influence obesity [7].

Childhood obesity is affected by the life style behavior. The playing habits of most children are centered toward the computer, television, mobiles, tablets and other electronic devices which decrease the physical activity. The adoption of a lifestyle, characterized by decreased physical activity and high caloric intake, is contributing to an alarming epidemiological pattern in many developing societies [8,9]. Therefore, health assessments and interventions at the primary care level are greatly needed to combat the increasing rates of childhood and adolescent obesity [10]

This study aimed to investigate lifestyle and dietary habits associated with development of obesity among male primary school children in Al-Madinah City, Saudi Arabia.

\section{Patients and Methods}

This study was conducted in 2014. A crosssectional study design was followed at primary schools in Al-Madinah City, Saudi Arabia.

Four study schools were selected by randomly from four geographic areas that have different socioeconomic status in Al-Madinah City, using a cluster sampling method. Classrooms were selected randomly and all students in a selected classroom were invited to participate in this study. Because of the expected communication problems, children below 8 years of age were excluded. The study included 201 male primary schoolchildren.

A study questionnaire was designed by the researcher. It included the following:

- Sociodemographic data of participants.

- The 19-item HABITS Questionnaire: It includes two subscales, i.e., dietary behaviors and physical activity/sedentary behavior, based on the 1998 Obesity Expert Committee recommendations [27] It assesses a variety of behaviors: e.g., eating regular meals, frequency of fruit and vegetable consumption, the consumption of beverages, (e.g., soft and energy drinks, time spent playing outside, watching television, and outdoor activity) during the last month.

Moreover, participants were physically examined and their anthropometric measurements were recorded. The BMI was calculated using the standard formula $\mathrm{BMI}=[$ Weight (in $\mathrm{kg}$ ) $] /[$ height (in meter) $]^{2}$. BMI measurements were plotted on the 2000 CDC Growth Charts [11]

Data were analyzed using the Statistical Package for Social Sciences (SPSS Version 17). Descriptive statistics for all variables were reported. Categorical data has been presented as frequency and percentage. All categorical variables were compared using the chi-square test. $p$-values less than 0.05 were considered as statistically significant.

\section{Results}

Age of participant schoolchildren ranged from 9 to 14 years, with a mean \pm SD of $11.2 \pm 1.1$ years. Fig. (1) shows that about two thirds of primary schoolchildren $(62.2 \%)$ were $11-12$ years old, $27.4 \%$ were $9-10$ old, and $10.4 \%$ were $13-14$ years old Fig. (1).

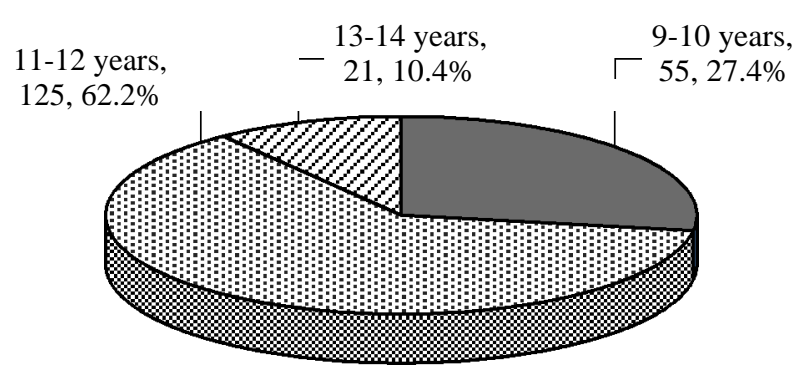

Fig. (1): Distribution of participants' age groups.

Prevalence of obesity among primary schoolchildren was $19.4 \%$. It was also found that $52.2 \%$ of participants showed normal weight and $9.5 \%$ of study participants were underweight, while $18.9 \%$ were overweight Fig. (2).

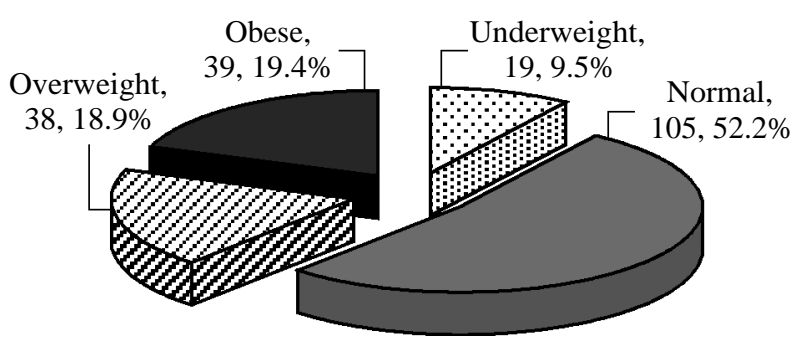

Fig. (2): Prevalence of obesity among participants.

Table (1) shows that during the last month, $59.7 \%$ of male primary schoolchildren ate three meals daily, $36.3 \%$ sometimes did that, while $4 \%$ did not eat three meals daily. Only $16.9 \%$ ate fruits daily, $79.1 \%$ sometimes ate fruits and $4 \%$ did not eat fruits. Regarding eating vegetables, only $17.9 \%$ ate vegetables daily, $71.1 \%$ sometimes ate vegetables and $10.9 \%$ did not eat vegetables. Most primary 
schoolchildren $(88.1 \%)$ ate snacks between meals. Regarding consuming soft and energy drinks, $42.3 \%$ consumed soft and energy drinks once a week or less, $26.9 \%$ consumed soft and energy drinks several times a week, $20.4 \%$ consumed soft and energy drinks once daily while $10.4 \%$ consumed soft and energy drinks twice or several times daily.

Table (1): Eating habits of male primary schoolchildren.

\begin{tabular}{lll}
\hline Habits & No. & $\%$ \\
\hline Eating three meals a day: & & \\
$\quad$ Once a week or less & 8 & 4.0 \\
Sometimes & 73 & 36.3 \\
$\quad$ Daily & 120 & 59.7 \\
Eating fruits: & & \\
$\quad$ Once a week or less & 8 & 4.0 \\
Sometimes & 159 & 79.1 \\
Daily & 34 & 16.9 \\
Eating vegetables: & & \\
Once a week or less & 22 & 10.9 \\
Sometimes & 143 & 71.1 \\
Daily & 36 & 17.9 \\
Eating snacks between meals: & & \\
$\quad$ Yes & 177 & 88.1 \\
$\quad$ No & 34 & 16.9 \\
Consuming soft and energy drinks: & & \\
Once a week or less & 85 & 42.3 \\
Several times a week & 54 & 26.9 \\
Once a day & 41 & 20.4 \\
More than once a day & 21 & 10.4 \\
\hline
\end{tabular}

Table (2) shows that during the last month, one third of male primary schoolchildren $(33.3 \%)$ watched TV for 3 hours or more, while during weekends, $66.2 \%$ watched TV for 3 hours or more. Regarding their outdoor activity, $19.4 \%$ practiced it once a week or less, $31.8 \%$ practiced it several times a week, $29.9 \%$ practiced it once a day, while $18.9 \%$ practiced it more than once a day.

Table (2): Participants' practices regarding watching TV and outdoor activity during last month.

\begin{tabular}{lll}
\hline Practices during last month & No. & $\%$ \\
\hline $\begin{array}{l}\text { Watching TV during weekdays: } \\
\quad \text { < One hour }\end{array}$ & 21 & \\
1 hours & 37 & 10.4 \\
2 hours & 76 & 37.8 \\
3 hours or more & 67 & 33.3 \\
Watching TV during weekends: & & \\
$\quad$ One hour & 8 & 4.0 \\
1 hour & 12 & 6.0 \\
2 hours & 48 & 23.9 \\
3 hours or more & 133 & 66.2 \\
Outdoor activity: & & \\
$\quad$ Once a week or less & 39 & 19.4 \\
$\quad$ Several times a week & 64 & 31.8 \\
$\quad$ Once a day & 60 & 29.9 \\
$\quad$ More than once a day & 38 & 18.9 \\
\hline
\end{tabular}

Fig. (3) shows that prevalence of obesity among/ primary schoolchildren was $14.5 \%$ among those aged 9-10 years, $19.2 \%$ among those aged 11-12 years and $33.3 \%$ among those aged $13-14$ years. Differences between age groups was statistically significant $(p<0.001)$.

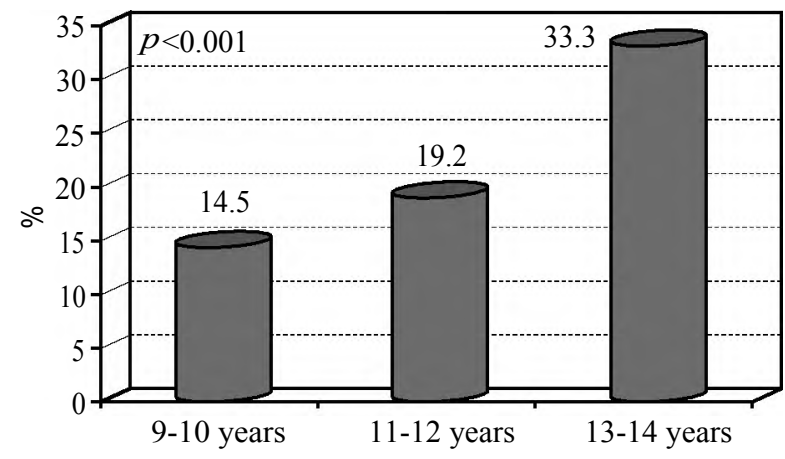

Fig. (3): Prevalence of obesity among primary schoolchildren according to their age groups.

Table (3) shows that consumption of soft and energy drinks was significantly higher among obese participants than non-obese ones $(p=0.035)$, with $20.5 \%$ of obese participants consuming soft and energy drinks more than once a day compared with only $8 \%$ of non-obese participants. However, all other studied eating habits did not differ significantly among participants according to their obesity status.

Table (3): Eating habits of study participants according to their obesity status.

\begin{tabular}{|c|c|c|c|}
\hline \multirow[b]{2}{*}{ Habits } & \multicolumn{2}{|c|}{ Obesity status } & \multirow{2}{*}{$\begin{array}{c}p- \\
\text { value }\end{array}$} \\
\hline & $\begin{array}{l}\text { Not Obese } \\
\quad(n=162)\end{array}$ & $\begin{array}{l}\text { Obese } \\
(n=39)\end{array}$ & \\
\hline $\begin{array}{l}\text { Eating three times a day } \\
\text { Once a week or less } \\
\text { Sometimes } \\
\text { Daily }\end{array}$ & $\begin{array}{l}6 \quad(3.7 \%) \\
59(36.4 \%) \\
97(59.9 \%)\end{array}$ & $\begin{array}{l}2 \quad(5.1 \%) \\
14(35.9 \%) \\
23(59 \%)\end{array}$ & 0.920 \\
\hline $\begin{array}{l}\text { Eating fruits: } \\
\text { Once a week or less } \\
\text { Sometimes } \\
\text { Daily }\end{array}$ & $\begin{array}{ll}6 & (3.7 \%) \\
129 & (79.6 \%) \\
27 \quad(16.7 \%)\end{array}$ & $\begin{array}{ll}2 & (5.1 \%) \\
30 & (76.9 \%) \\
7 & (17.9 \%)\end{array}$ & 0.896 \\
\hline $\begin{array}{l}\text { Eating vegetables: } \\
\text { Once a week or less } \\
\text { Sometimes } \\
\text { Daily }\end{array}$ & $\begin{array}{l}18(11.1 \%) \\
115(71.0 \%) \\
29 \quad(17.9 \%)\end{array}$ & $\begin{array}{ll}4 & (10.3 \%) \\
28 & (71.8 \%) \\
7 & (17.9 \%)\end{array}$ & 0.988 \\
\hline $\begin{array}{l}\text { Eating snacks between } \\
\text { meals: } \\
\text { Yes } \\
\text { No }\end{array}$ & $\begin{array}{l}143(88.3 \%) \\
19(11.7 \%)\end{array}$ & $\begin{array}{ll}34 & (87.2 \%) \\
5 & (12.8 \%)\end{array}$ & 0.517 \\
\hline $\begin{array}{l}\text { Consumption of soft and } \\
\text { energy drinks: } \\
\text { Once a week or less } \\
\text { Several times a week } \\
\text { Once a day } \\
\text { More than once a day }\end{array}$ & $\begin{array}{l}75(46.3 \%) \\
41(25.3 \%) \\
33(20.4 \%) \\
13(8.0 \%)\end{array}$ & $\begin{array}{ll}10 & (25.6 \%) \\
13 & (33.3 \%) \\
8 & (20.5 \%) \\
8 & (20.5 \%)\end{array}$ & 0.035 \\
\hline
\end{tabular}


Table (4) shows that outdoor activity was significantly higher among non-obese participants than obese ones ( $p=0.027)$, with $15.4 \%$ of nonobese participants practicing outdoor activity once a week or less compared with $35.9 \%$ of obese participants; and $20.4 \%$ of non-obese participants practicing outdoor activity more than once a day compared with only $12.8 \%$ of obese participants. However, watching TV during weekdays or weekends did not differ significantly among participants according to their obesity status.

Table (4): Participants' watching TV and outdoor activity according to their obesity status.

\begin{tabular}{|c|c|c|c|}
\hline \multirow[b]{2}{*}{ Variables } & \multicolumn{2}{|c|}{ Obesity status } & \multirow{2}{*}{$\begin{array}{c}p- \\
\text { value }\end{array}$} \\
\hline & $\begin{array}{l}\text { Not Obese } \\
(\mathrm{n}=162)\end{array}$ & $\begin{array}{l}\text { Obese } \\
(n=39)\end{array}$ & \\
\hline \multicolumn{4}{|l|}{$\begin{array}{l}\text { Watching TV during } \\
\text { weekdays: }\end{array}$} \\
\hline$<$ One hour & $14(8.6 \%)$ & $7 \quad(17.9 \%)$ & \\
\hline 1 hour & $30(18.5 \%)$ & $7 \quad(17.9 \%)$ & \\
\hline 2 hours & $61(37.7 \%)$ & $15(38.5 \%)$ & 0.324 \\
\hline 3 hours or more & $57(35.2 \%)$ & $10(25.6 \%)$ & \\
\hline \multicolumn{4}{|l|}{$\begin{array}{l}\text { Watching TV during } \\
\text { weekend: }\end{array}$} \\
\hline$<$ One hour & $(3.7 \%)$ & $2(5.1 \%)$ & \\
\hline 1 hour & $7 \quad(4.3 \%)$ & $5 \quad(12.8 \%)$ & 0.226 \\
\hline 2 hours & $39(24.1 \%)$ & $9 \quad(23.1 \%)$ & \\
\hline 3 hours or more & $110(67.9 \%)$ & $23(59.0 \%)$ & \\
\hline \multicolumn{4}{|l|}{ Outdoor activity: } \\
\hline Once a week or less & $25(15.4 \%)$ & $14(35.9 \%)$ & \\
\hline Several times a week & $52(32.1 \%)$ & $12(30.8 \%)$ & \\
\hline Once a day & $52(32.1 \%)$ & $8 \quad(20.5 \%)$ & 0.027 \\
\hline More than once a day & $33(20.4 \%)$ & $5 \quad(12.8 \%)$ & \\
\hline
\end{tabular}

\section{Discussion}

Results of the current study showed that prevalence of obesity among male primary schoolchildren in Al-Madinah City was high (19.4\%), with a significantly increasing trend with their age.

The high prevalence rate for obesity among male primary schoolchildren in Al-Madinah City is in agreement with those reported in several other parts of Saudi Arabia. In Makkah, Al-Shehri [12] reported that prevalence of obesity among male school children aged 6-12 years was $20.2 \%$, while in Tabuk, Al-Enazy [13] reported that prevalence of obesity among male school children aged 6-12 years was $17.4 \%$. however, in USA, Gauthier et al., [14] reported that prevalence of obesity among primary schoolchildren ranges from $6 \%$ to $30 \%$.

Steinbeck, [15] explained the increasing prevalence rates of obesity among schoolchildren with their age by the associated decrease in their physical activity with age. Moreover, Kelishadi et al., [16] added that, the rapid progress of urbanization is associated with unhealthy lifestyles described as the "lifestyle syndrome" or the "New World syndrome". This is suggested as the most important etiology for the high rates of obesity and its consequent morbidity and mortality in developing nations. In addition, childhood obesity is still wrongly considered by most communities as a sign of healthiness and high social class.

The present study revealed that most male primary schoolchildren do not follow healthy eating habits. Only $59.7 \%$ ate three meals daily, daily consumption of fruits and vegetables have been fulfilled by only $16.9 \%$ and $17.9 \%$, respectively, and $88.1 \%$ ate snacks between meals.

Similarly, Ku zbicka and Racho $\mathrm{n}$ [17] reported that most school children have improper eating behaviors. They usually consume excess amounts of energy and their diet is deficient in elements necessary for proper development. Examples of such bad eating habits comprise skipping breakfasts and drinking sugar-sweetened beverages. Such bad eating behaviors are crucial factors for the development of obesity.

Nevertheless, no statistically significant differences were observed in the present study between obese and non-obese male primary schoolchildren according to their number of daily meals, consumption of fruits or consumption of vegetables.

These results are in accordance with those of Krebs et al., [18] and Ledoux et al., [19], who concluded that evidence regarding the relation of fruit and vegetable consumption with obesity among children is inconsistent. On the other hand, some other studies reported that consumption of fruits and vegetables were related to obesity prevention in children [20-22]

The discrepancy between results reported by different studies regarding the negative association between fruits and vegetables intake and obesity among children reflects the fact that obesity is a multifactorial etiology, where weight gain can be the resultant of interactions between numerous factors [6].

Findings of the present study showed that $20.4 \%$ of participants consumed soft and energy drinks once daily while $10.4 \%$ consumed soft and energy drinks more than once daily. Moreover, consumption of soft and energy drinks was significantly higher among obese participants. 
These findings are in accordance with those of Katzmarzyk et al., [23] who noted that the consumption of sugar-sweetened beverages is common among children. They also reported a positive association between obesity among schoolchildren and their consumption of sugar-sweetened beverages. Keller and Bucher Della Torre [24] added that systematic reviews showed direct associations between sugar-sweetened beverages consumption and weight gain and obesity in children and adolescents. Furthermore, several prospective studies that included repeated measures of both soft drinks and weight found that an increase in the consumption of sugary soft drinks was significantly associated with greater weight gain and greater risk of obesity over time in children $[\mathbf{2 5 , 2 6 ]}$.

The present study showed that, during weekdays, one third of participants watched TV for 3 hours or more, while during weekends, two thirds of participants watched TV for 3 hours or more. Moreover, only $29.9 \%$ practiced it once a day, and $18.9 \%$ practiced it more than once a day. Although duration of watching TV did not differ significantly according to presence of obesity among participants, outdoor activity was significantly higher among non-obese participants than obese ones.

Rosiek et al., [27] found that, on average, children aged 2-14 years spend 2.4 hours a day in front of a TV screen. They added that besides the fact that watching television contributes to physical inactivity, commercials and other programs also encourage children to eat more. Moreover, TV viewing takes away from the time children spend on physical activities and also leads to increased energy intake through snacking and eating meals in front of the TV. Those habits of "sit time" and "snacks", and also product advertisements on TV, influence children to make unhealthy food choices and follow bad eating habits $[28,29]$.

Steinbeck [15] noted that lower physical activity levels and sedentary behaviors are significantly associated with a higher prevalence of obesity in children. In Saudi Arabia, Al-Hazzaa [30] stated that children and adolescents have adopted a less active lifestyle and seem to have become obese. $\mathrm{He}$ argued that Saudi children expend less energy in their daily activities compared with their counterparts three or four decades ago and the proportion of Saudi youth who are inactive and/or obese from childhood to early adulthood has substantially increased.

The main limitation of the present study is related to the self-reporting nature of data provided by schoolchildren. Self-reporting of dietary intake is often "under-estimated" [31], whereas selfreporting of physical activity is often "overestimated" [32] . Moreover, the generalizability of our results is restricted to male primary school children only.

In conclusion, bad nutritional habits are common among male primary schoolchildren. Prevalence of obesity among male primary school children is high and increases with their age. Consumption of soft and energy drinks and lack of physical activity are significantly associated with obesity among children. Therefore, there is a pressing need for the development of effective obesity prevention programs for schoolchildren. Health education of schoolchildren to encourage daily practice of physical activity, proper nutritional habits encourage daily intake of fruits and vegetables and avoidance of excessive consumption of soft and energy drinks. Further studies are needed to explore lifestyle and dietary habits associated with development of obesity among female schoolchildren and those in other areas of Saudi Arabia.

\section{References}

1- FLEGAL K.M., WEI R. and OGDEN C.: Weight-forstature compared with body mass index-for-age growth charts for the United States from the Centers for Disease Control and Prevention. Am. J. Clin. Nutr., 75 (4): 761 6, 2002 .

2- World Health Organization. Obesity: Preventing and Managing the Global Epidemic. Technical Report Series. Geneva, Switzerland: WHO, 2005.

3- HASLAM D.W. and JAMES W.P.: Obesity. Lancet, 366 (9492): 1197-209, 2005.

4- KELSEY M.M., ZAEPFEL A., BJORNSTAD P. and NADEAU K.J.: Age-related consequences of childhood obesity. Gerontology, 60 (3): 222-8, 2014.

5- ALMUHANNA M.A., ALSAIF M., ALSAADI M. and ALMAJWAL A.: Sudanese J. Paediatr., 14 (1): 71-80, 2014.

6- GRUNDY S.M.: Multifactorial causation of obesity: Implications for prevention. Am. J. Clin. Nutr., 67 (3 Suppl): 563S-72S, 1998.

7- LINK K., MOELL C., GARWICZ S., CAVALLINSTAHL E., BJORK J., THILEN U., et al.: Growth hormone deficiency predicts cardiovascular risk in young adults treated for acute lymphoblastic leukemia in childhood. J. Clin. Endocrinol. Metab., 89 (10): 5003-12, 2004.

8- BOUTAYEB A. and BOUTAYEB S.: The burden of noncommunicable diseases in developing countries. Int. J. Equity Health, 4 (1): 2, 2005.

9- AMUNA P. and ZOTOR F.B.: Epidemiological and nutrition transition in developing countries: Impact on human health and development. Proc. Nutr. Soc., 67 (1): 82-90, 2008 . 
10- OGDEN C.L., CARROLL M.D. and FLEGAL K.M.: High body mass index for age among US children and adolescents, 2003-2006. J.A.M.A., 299 (20): 2401-5, 2008.

11- KUCZMARSKI R.J., OGDEN C.L., GUO S.S., et al.: 2000 CDC growth charts for the United States: Methods and development. National Center for Health Statistics. Vital. Health Stat., 11: 246, 2002.

14- GAUTHIER B.M., HICKNER J.M. and NOEL M.M.: High prevalence of overweight children in Michigan primary care practices. An UPRNet study. Upper Peninsula Research Network. J. Fam. Pract., 49 (1): 73-6, 2000.

15- STEINBECK K.S.: The importance of physical activity in the prevention of overweight and obesity in childhood: A review and an opinion. Obes. Rev., 2 (2): 117-30, 2001.

12- AL-SHEHRI J.A.: Childhood obesity among primary school boys at Al-Iskan sector, Holy Makkah in Saudi Arabia. Int. J. Med. Sci. Public Health, 3 (2): 150-5, 2014.

13- AL-ENAZY W.H., AL-ENAZY F.S., AL-ENAZY F.A and AL-QAHTANI M.A.: Prevalence of overweight and obesity among Saudi primary school students in Tabuk, Saudi Arabia. Int. J. Med. Sci. Public Health, 3 (8): 993 9, 2014.

16- KELISHADI R.: Childhood overweight, obesity, and the metabolic syndrome in developing countries. Epidemiol. Rev., 29: 62-76, 2007.

17- KUZBICKA K. and RACHON D.: Bad eating habits as the main cause of obesity among children. Pediatr Endocrinol Diabetes Metab., 19 (3): 106-10, 2013.

18- KREBS N.F., HIMES J.H., JACOBSON D., NICKLAS T.A., GUILDAY P. and STYNE D.: Assessment of child and adolescent overweight and obesity. Pediatrics, 120 (Suppl 4): S193-S228, 2007.

19- LEDOUX T.A., HINGLE M.D. and BARANOWSKI T.: Relationship of fruit and vegetable intake with adiposity: A systematic review. Obes. Rev., 12 (5): e143-e150, 2011.

20- MALIK V.S., SCHULZE M.B. and HU F.B.: Intake of sugar-sweetened beverages and weight gain: A systematic review. Am. J. Clin. Nutr., 84 (2): 274-88, 2006.

21- DAVIS M.M., GANCE-CLEVELAND B., HASSINK S., JOHNSON R., PARADIS G. and RESNICOW K.: Recommendations for prevention of childhood obesity. Pediatrics, 120 (Suppl 4): S229-S253, 2007.
22- SPEAR B.A., BARLOW S.E., ERVIN C., LUDWIG D.S., SAELENS B.E., SCHETZINA K.E., et al.: Recommendations for treatment of child and adolescent overweight and obesity. Pediatrics, 120 (Suppl 4): S254-S288, 2007.

23- KATZMARZYK P.T., BROYLES S.T., CHAMPAGNE C.M., CHAPUT J., FOGELHOLM M., HU G., et al.: Relationship between Soft Drink Consumption and Obesity in 9-11 Years Old Children in a Multi-National Study. Nutrients, 8 (12): 770, 2016.

24- KELLER A. and BUCHER DELLA TORRE S.: SugarSweetened Beverages and Obesity among Children and Adolescents: A Review of Systematic Literature Reviews. Child. Obes., 11 (4): 338-46, 2015.

25- LUDWIG D.S., PETERSON K.E. and GORTMAKER S.L.: Relation between consumption of sugar-sweetened drinks and childhood obesity: A prospective, observational analysis. Lancet, 357: 505-8, 2001.

26- BERKEY C.S., ROCKETT H.R., FIELD A.E., GILLMAN M.W. and COLDITZ G.A.: Sugar-added beverages and adolescent weight change. Obes. Res., 12: 778-88, 2004.

27- ROSIEK A., MACIEJEWSKA N.F., LEKSOWSKI K., ROSIEK-KRYSZEWSKA A. and LEKSOWSKI L.: Effect of Television on Obesity and Excess of Weight and Consequences of Health. Int. J. Environ. Res. Public Health, 12 (8): 9408-26, 2015.

28- ROBINSON T.N.: Television viewing and childhood obesity. Pediatr. Clin. North Am., 48: 1017-102, 2001.

29- ZIMMERMAN F.J. and BELL J.F.: Associations of television content type and obesity in children. Am. J. Public Health, 100: 334-40, 2010.

30- AL-HAZZAA H.M.: Obesity and physical inactivity among Saudi children and youth: Challenges to future public health. J. Family Community Med., 13 (2): 53-4, 2006.

31- SCHOELLER D.A.: Limitations in the assessment of dietary energy intake by self-report. Metabolism, 44: 1822, 1995.

32- ADAMS S.A., MATTHEWS C.E., EBBELING C.B., MOORE C.G., CUNNINGHAM J.E., FULTON J. and HERBERT J.R.: The effect of social desirability and social approval on self-reports of physical activity. Am. J. Epidemiol., 161: 389-98, 2005. 


\section{معدل إنتشار السمنة وعلاوقتها مع عادات الآكل ونمط الحئ الحياة

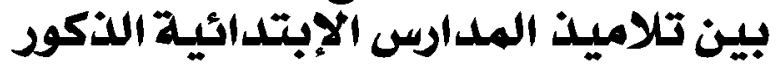

هدف البحث: دراسة نمط الحياة والعادات الغذائية المرتبطة بالسمنة لدى آطفال المدارس الإبتدائية بالمدينة المنودة، المملكة العريية

السعودية.

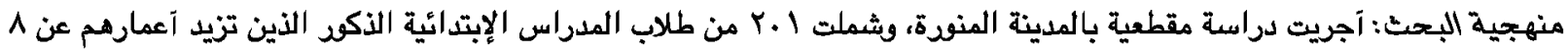

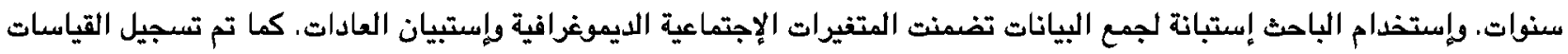

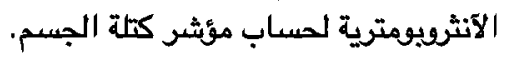

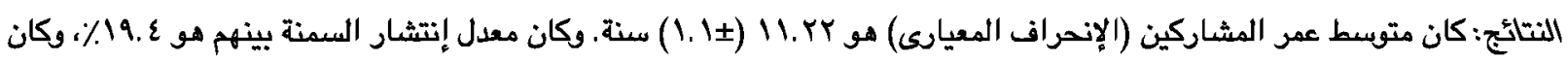

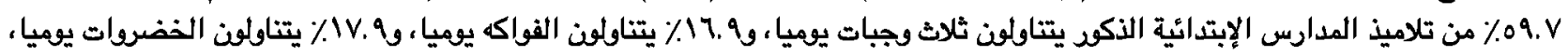

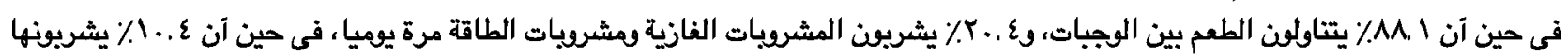

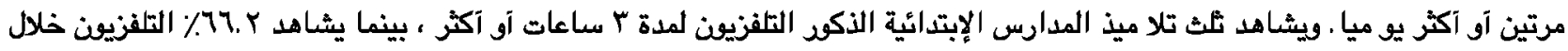

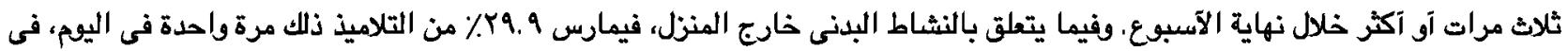

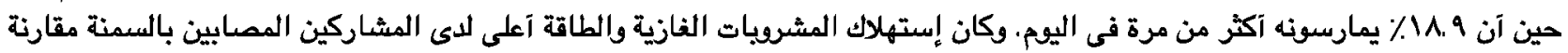

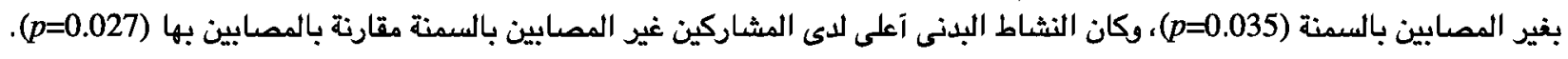

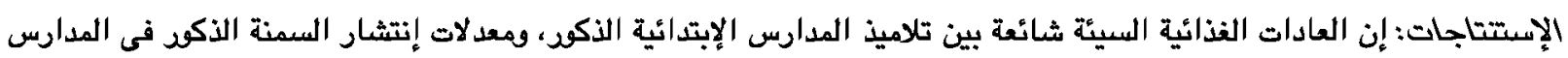

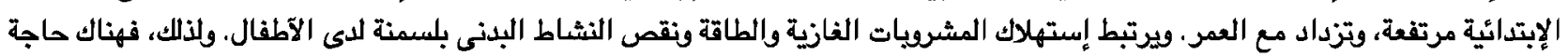

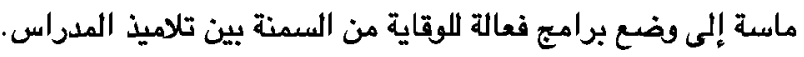

